상급종합병원에서의 간호 · 간병통합서비스 병동과 일반병동 간호사의 근무환경, 역할갈등, 직무 배태성 비교 소혜은 ${ }^{1}$, 황지인 ${ }^{2}$

1강북삼성병원 간호본부, ${ }^{2}$ 경희대학교 간호과학대학

\title{
A Comparison of Nursing Work Environment, Role Conflict, and Job Embeddedness of Nurses Working in Comprehensive Nursing Care Service Wards and General Wards in a Tertiary Hospital
}

\author{
Hye-Eun So', Jee-In Hwang ${ }^{2}$ \\ ${ }^{1}$ Nurse, Department of Nursing, Kangbuk Samsung Hospital, ${ }^{2}$ Professor, College of Nursing Science, Kyung Hee University
}

Purpose: The objective of this study was to compare and analyze the work environment, role conflict, and job embeddedness between comprehensive nursing care service (CNCS) ward nurses and general ward nurses.

Methods: This descriptive research study involved 70 CNCS ward nurses and 69 general ward nurses working at an advanced general hospital in Seoul. Data were collected using the structured questionnaire from March 27 to April 14, 2019 and analyzed with the SPSS 24.0 program.

Results: The work environment of the CNCS ward nurse was higher than that of the general ward nurse $(\mathrm{t}=4.38, p<.001)$, and the role conflict of the CNCS ward nurse was lower than that of the general ward nurse $(\mathrm{t}=-2.09, p=.038)$. However, job embeddedness did not show any statistically significant difference $(\mathrm{t}=0.22, p=.824)$.

Conclusion: The results of this study show that the introduction of CNCS ward has shown improvement in the work environment and strengthened the establishment of the roles in their team, while maintaining the job embeddedness of nurses. These results indicate that improvements in the work environment, such as nurse staffing and material support, would contribute to the qualitative enhancement of nursing and that it would need to extend the introduction of CNCS wards.

Keywords: Nurses, Nurse's role, Job satisfaction, Workplace, Environment

Received: Dec.04.2019 Revised: Mar.16.2020 Accepted: Mar.20.2020

Correspondence: Jee-In Hwang

Kyung Hee University College of Nursing Science Kyungheedae-ro 26, Dongdaemun-gu, Seoul, 02247, Republic of Korea

Tel: +82-2-961-9145 Fax:+82-2-961-9398 E-mail: jihwangakhu.ac.kr

Funding: None Conflict of Interest: None

Acknowledge: This article is a condensed form of the first author's master's thesis from Graduate School of Education Kyung Hee University.

Quality Improvement in Health Care vol.26 no.1

(c) The Author 2020. Published by Korean Society for Quality in Health Care; all rights reserved

11 Quality Improvement in Health Care 


\section{|. 서론}

\section{1. 연구의 필요성}

의료기술의 발달로 만성질환자가 증가하며 핵가족화, 인 구의 고령화 등의 사회적 변화로 인해[1] 환자의 돌봄과 간 병에 소요되는 가족의 신체적, 경제적 비용 부담이 급속히 가중되고 있고[2], 또한 핵가족화로 인해 가족 중에 환자가 발생해도 간병을 할 수 있는 구성원이 없어 어려움을 겪고 있다[3]. 이를 해결하고자 정부는 가족이나 개인 유료 간병 인이 해 왔던 환자 간병을 2013년부터 간호사와 간호조무 사로 간호 인력을 확충하여 간병을 포함한 포괄적 간호 서 비스를 시범적으로 시행하였고[4], 2016년부터는 간호. 간병통합서비스로 명칭을 바꾸어 중소병원 뿐만 아니라 점 차적으로 상급종합병원까지 확대 적용하였다[5].

간호 · 간병통합서비스는 정부가 국민의 간병부담 경감 을 위해 적극적으로 추진하고 있는 사업으로 적정 제공인 력 배치를 통한 팀 간호체계의 총체적인 전문 간호 제공과 병동 환경개선 및 환자 안전관리 등 간호 · 간병통합서비스 제공에 필요한 여건을 갖춘 병동에서 제공하는 입원서비 스를 의미한다[5]. 간호 - 간병통합서비스는 병동단위로 운 영되어 환자 입원에 따르는 모든 간호 - 간병서비스를 병원 의 책임 하에 제공하며 사적 고용 간병인이나 보호자의 상 주를 제한하는 한편, 그에 따른 병문안 기준을 마련하여 운 영하는 등, 쾌적한 입원 환경을 제공하고 있고[6], 2018년 12 월 기준 누적 제공병상 3만7천여 병상에 달하며 전국적 으로 495 개 기관이 간호 간병통합서비스 병동을 운영하 고 있다[7].

간호 · 간병통합서비스란 이름으로 제도를 수립하고 운 영 · 정착되는 동안에 환자 측면에서의 연구결과들을 살펴 보면 간호 · 간병통합서비스 병동을 이용하는 환자들의 간 호 요구도와 간호서비스 만족도가 높았고[2], 간호·간병 통합서비스 병동의 환자가 일반병동 환자들보다 병원 몰 입, 재이용의사가 높은 것을 확인하였다[8]. 또한 환자에게 큰 영향을 미치는 욕창, 낙상, 병원 내 감염과 같은 환자안 전지표도 향상되었다[9]. 이 같은 이유는 간호 · 간병통합
서비스 병동에서 환자에게 제공되는 직접간호시간이 증가 하고, 간호사가 환자안전에 위험이 될 수 있는 요인들을 지 속적으로 관찰한 결과로[10], 간호·간병통합서비스 적용 이후 간호사들은 역할수행범위와 근무환경의 변화를 경험 하고 있다[11].

간호근무환경은 전문적 간호수행을 강화하거나 제한시키 는 업무환경의 조직적 특성으로 정의될 수 있다[12]. 일반 병동에서의 간호사 1 인당 환자수가 10 명에서 30 명의 환 자수를 담당하고 있는 것에 비해[13] 간호 - 간병통합서비 스의 인력배치는 환자특성, 병상 가동률, 중증도 · 간호필 요도, 진료과의 특성을 고려하여[5] 간호사 1 인당 환자 수 가 상급종합병원은 5 7명, 종합병원은 7 12명, 병원은 10 16명의 환자를 담당하고 있어 병원들마다 근무환경의 차이가 있다[6]. 또한 간호 · 간병통합서비스 병동에서는 간호사 뿐 아니라 간호조무사, 간병지원인력으로 구성되어 업무 보조를 받고 있는데, 이처럼 일반병동에 근무하는 간 호사와의 업무량 차이가 있어[9] 두 병동 간호사들이 경험 하는 간호근무환경의 인식에 대해 알아 볼 필요가 있다.

역할갈등이란 역할을 실제로 수행하는 사람이 자신의 기 대에 일치되지 않는 행위로 인하여 경험하는 긴장 및 어려 운 상황을 말한다[14]. 간호사의 역할갈등의 원인은 다양 한 상황에서 발생되나 이중 병원 간호사들은 간호업무와 환자/보호자와의 관계에서 역할갈등을 자주 경험하고 있 고, 간호업무와 관련된 역할갈등에서 빈도와 심각성이 모 두 높게 나타났다[15]. 하지만 간호 · 간병통합서비스 병동 간호사는 역할갈등의 가장 큰 요인으로 업무 외에 일상생 활지원업무까지 맡아 하는 역할 업무를 꼽았다[16]. 간호 근무환경은 간호사의 직무만족 및 이직의도에 가장 큰 영 향을 미치는 변수이다[17]. 앞서 언급한 데로 두 병동의 간 호사들이 경험하는 간호근무환경과 업무에는 차이가 있고 [9], 이로 인해 지각하는 역할갈등의 요인들도 달라 간호 . 간병통합서비스 병동과 일반병동 간호사의 역할갈등의 차 이 확인이 필요하며 영향을 미치는 요인에 대해 알아볼 필 요가 있다.

직무 배태성(job embeddedness)은 개인이 직무와 높 은 연관성을 가지고 깊이 뿌리를 내리고 있는 정도로서, 조 
직 내 잔류를 매개해 주는 핵심으로 제시되고 있다[18]. 직 무 배태성은 연계(links), 적합성(fit), 희생(sacrifice)의 3 가지 핵심요소로 구성된다[18]. 연계는 조직이나 지역사회 내 사람들과 사회적, 심리적 관계 및 연결정도를 의미하고 적합성은 개인이 조직과 지역사회 커뮤니티에 잘 맞는다고 지각하는 정도이며 희생은 조직이나 지역사회를 떠남으로 써 얻게 되는 손해를 말한다[18]. 병원조직 내에서 가장 큰 전문 인력인 간호사들의 생산성과 그에 관한 관리의 중요 성이 높아 지고 간호사의 이직은 병원의 손실비용 문제로 까지 확산되고 있다[19]. 하지만 이직의 원인이 직무만족 이나 조직몰입 등과 같이 직무태도 등을 중심으로 파악되 어 이직을 설명하는 대에는 한계가 있어[20], 이직이 발생 하는 과정보다 이직 발생하지 않도록 하는 원인과 과정을 확인하는 직무 배태성에[21] 대하여 알아보고자 한다. 직 무 배태성을 증가시킴으로써 간호사의 이직의도를 감소시 킬 수 있고[22], 간호 - 간병통합서비스를 제공하는 간호사 를 대상으로 했던 연구에서도 이직의도에 상대적으로 영향 력이 제일 큰 요인으로 직무 배태성을 꼽았다[23]. 그러므 로 효율적인 병동 운영 및 간호사의 인적자원 관리를 위하 여 간호 - 간병통합서비스 병동과 일반병동 간호사의 직무 배태성에 대하여 알아보고자 하며, 현재까지 간호 - 간병통 합서비스 병동과 일반병동 간호사의 직무 배태성에 대하여 비교 분석한 연구가 없어 이를 확인해 볼 필요가 있다.

이에 이 연구에서 상급종합병원에서의 간호 · 간병통합서 비스 병동 간호사와 일반병동 간호사의 근무환경, 역할갈 등, 직무 배태성의 차이를 확인하고, 근무환경, 역할갈등, 직무 배태성 간의 관계를 파악함으로써, 간호 - 간병통합서 비스 병동 도입에 따른 간호의 질적 향상을 위한 기초자료 를 제공할 것이다.

\section{2. 연구의 목적}

이 연구의 목적은 간호 - 간병통합서비스 병동 간호사와 일반병동 간호사의 근무환경, 역할갈등, 직무 배태성을 비 교, 분석하고 간호근무환경, 역할갈등, 직무 배태성 간의 관계를 파악함으로써, 간호 - 간병통합서비스 병동 도입에
따른 간호의 질적 향상을 위한 기초자료를 제공하기 위함 이며 구체적인 목적은 다음과 같다.

- 간호 - 간병통합서비스 병동 간호사와 일반병동 간호사 의 근무환경, 역할갈등, 직무 배태성의 차이를 비교, 분 석한다.

- 간호 - 간병통합서비스 병동과 일반병동 간호사의 근무 환경과 역할갈등 및 직무 배태성 간의 관계를 확인한다.

\section{II. 연구방법}

\section{1. 연구 설계}

이 연구는 간호 · 간병통합서비스 병동 간호사와 일반병 동 간호사의 근무환경, 역할갈등, 직무 배태성을 비교, 분 석하고 근무환경, 역할갈등, 직무 배태성 간의 관계 확인을 위한 서술적 조사 연구이다.

\section{2. 연구 대상}

이 연구에서는 서울시 소재의 상급종합병원인 $\mathrm{K}$ 종합병 원에 입사하여 3 개월간의 기본 및 심화과정 교육을 받은 후 독립적인 팀 업무를 맡은 지 3개월이 지난 시점인 6개 월 이상의 경력을 가지며, 병동업무파악 기간을 고려하여 3 개월 이상 내 - 외과 간호 - 간병통합서비스 병동과 일반 병동에 근무한 간호사로 이 연구의 목적을 이해하고 연구 참여에 동의한 자를 대상으로 편의 표집 하였다. 이 연구 에서 각 집단에 필요한 자료수집 대상자의 수는 $\mathrm{G}^{*}$ power 3.1.9.2 프로그램을 이용하여 독립표본 t-test에서 검정력 $(1-\beta)=0.8$, 유의수준 $\alpha=0.05$, 중간효과크기 $\mathrm{d}=0.5$ 로 산 출한 결과[28], 총 표본수가 128 명으로 각 집단별로 64 명 이 요구되지만 탈락률(10\%)를 고려하여 각 집단별로 70명 씩 총 140 명을 대상으로 하였다. 미 수거된 1건을 제외하 고 간호 · 간병통합서비스 병동 간호사 70 명, 일반병동 간 호사 69명, 총 139명(99.3\%)의 설문지가 최종 자료 분석 에 사용되었다. 


\section{3. 연구 도구}

이 연구에서는 구조화된 자가 보고형 설문지를 사용하였 으며 내용은 일반적 특성 11문항, 근무환경 29문항, 역할 갈등 37 문항, 직무 배태성 18 문항으로 총 95 문항으로 구 성되었다.

\section{1) 일반적 특성}

이 연구에서 일반적 특성은 성별, 연령, 결혼상태, 최종학 력, 임상경력, 현재직위, 근무형태, 주 진료과, 교차 근무 여부, 연봉, 연봉만족여부 등 11 문항으로 구성되었다.

\section{2) 근무환경}

이 연구에서의 근무환경은 Lake [12]가 개발한 PESNWI (Practice Environment Scale of Nursing Work Index)를 Cho 등[24]이 우리나라 실정에 맞게 번안하여 신뢰도와 타당도를 검증한 한국어판 간호업무환경 측정도 구 K-PES-NWI (Korea Practice Environment Scale of the Nursing Work Index)를 도구 사용에 대한 승인을 메일로 받아 사용하였다. 본 도구는 '병원운영에 간호사 참 여' 9문항, '양질의 간호를 위한 기반' 9문항, '간호 관리자 의 능력, 리더십, 간호사에 대한지지' 4 문항, '충분한 인력 과 물질적 자원의 적절성' 4 문항, '간호사와 의사의 협력관 계' 3문항으로 총 5개 영역 29문항의 4점 척도로 구성되어 있다. 각 문항은 '전혀 그렇지 않다' 1점에서 '매우 그렇다' 4점까지의 4점 Likert 척도로 점수의 범위는 최저 29점에 서 최고 116 점이고, 점수가 높을수록 간호사가 간호단위의 근무환경에 대해 긍정적으로 인식하고 있음을 의미한다. 미국에서 개발 당시 PES-NWI의 신뢰도는 Cronbach's $\alpha$ 는 .82이었고[12], 한국어판 K-PES-NWI의 신뢰도를 분 석한 결과 전체 문항에 대한 Cronbach's $\alpha$ 는 .93이며 [24], 이 연구에서의 Cronbach's $\alpha$ 는 .94 이었다.

3) 역할갈등
이 연구에서의 역할갈등은 $\mathrm{Kim}$ 등[14]이 House 등[25] 의 역할갈등 및 모호성 척도를 분석하여 한국적 상황 특히 간호사들이 병원 생활에서 경험하는 역할갈등을 측정하기 위해 개발한 도구를 개발자에게 도구 사용에 대한 승인을 메일로 받아 사용하였다. 간호사들이 업무를 수행하는 과 정에서 경험한 역할갈등을 '역할 모호' 15 문항, '환경장애' 6문항, ‘협조부족' 5 문항, '능력부족' 11 문항의 4 개의 갈등 상황 영역으로 구분하였고, 도구의 문항은 총 37 문항으로 구성 되어있다. 각 문항은 '전혀 그렇지 않다' 1 점에서 '매 우 그렇다' 5점까지의 5점 Likert 척도로 점수 범위는 최 저 37점에서 최고 185 점이고 점수가 높을수록 역할갈등 이 높음을 의미한다. House 등[25]의 연구에서 전체 문항 에 대한 Cronbach's $\alpha$ 는 .94 이었고, 4 개 요인 별 Cronbach's $\alpha$ 는 .90, .84, .60, .60이었다. Kim 등[14]의 전체 문항에 대한 Cronbach's $\alpha$ 는 .94이었으며[14], 이 연구에 서의 Cronbach's $\alpha$ 는 .96 이었다.

4) 직무 배태성

이 연구에서의 직무 배태성 측정도구는 Mitchell 등[18] 이 개발한 도구를 $\mathrm{Kim}$ 등[22]이 번안한 도구를 사용에 대 한 승인을 받아 사용하였다. 이 도구는 개발 당시 지역사회 및 조직의 두 가지 차원에 대해 적합성, 연계, 희생의 세 가 지 요인으로 구성되었으나, 병원 직원을 대상으로 한 결과 에서 지역사회와의 연계, 지역사회와 관련된 희생의 신뢰 도가 $.50, .59$ 로 낮게 나타났다. $\mathrm{Kim}$ 등[22]의 연구에서 는 조직 차원에 대한 문항만을 사용하여 직무 배태성을 측 정하고 있다. 다른 구성원들과 연결된 정도를 의미하는 '연 계' 4문항, 구성원이 자신이 현재 수행하고 있는 직무, 기 업, 조직 및 지역사회가 자신과 잘 맞는다고 느끼는 '적합 성 8 문항, 직장을 이직할 경우 발생되는 심리적, 물질적 손해를 나타내는 ‘희생' 6 문항의 3 개의 하위개념으로 구분 하였고, 도구의 문항은 총 18 문항으로 구성 되어있다. 각 문항은 '전혀 그렇지 않다' 1점에서 '매우 그렇다' 5점까지 의 5점 Likert 척도로 점수 범위는 최저 18점에서 최고 90 점이고 점수가 높을수록 직무 배태성이 높음을 의미한다. 
Mitchell 등[18]의 연구에서 신뢰도는 전체 문항에 대해서 Cronbach's $\alpha$ 는 .87이었고, 각 하부 척도 Cronbach's $\alpha$ 는 .86, .62, .82 이었다. $\operatorname{Kim}$ [22] 연구에서 도구 신뢰 도 Cronbach's $\alpha$ 는 .87이었으며, 이 연구에서의 Cronbach's $\alpha$ 는 .91 이었다.

\section{4. 자료수집 방법}

서울시 소재의 상급종합병원인 $\mathrm{K}$ 종합병원의 내· 외과 간호 · 간병통합서비스 병동과 일반병동에 재직중인 간호 사를 대상으로 편의 표집하여, 연구 대상 병원의 간호본부 교육 팀장과 해당 병동 파트장에게 연구 목적과 방법을 설 명하고 자료 수집에 대한 승인을 얻은 후, 설문지는 연구자 가 해당 병동에 방문하여 이 연구목적을 이해하고 참여를 허락한 간호사에게 서면 동의를 받은 후 2019년 3월 27일 부터 4월 14일까지 수집하였다.

\section{5. 자료분석 방법}

수집된 자료는 SPSS 24.0 program를 이용하여 통계처 리 하였고, 구체적인 방법은 다음과 같다.

- 간호 - 간병통합서비스 병동과 일반병동 간호사의 일반 적 특성은 빈도, 백분율, 카이제곱검정을 이용 하였다.

- 간호 - 간병통합서비스 병동과 일반병동 간호사의 근무 환경, 역할갈등, 직무 배태성을 알아보기 위하여 평균 및 표준 편차를 구하였다.

- 간호 - 간병통합서비스 병동과 일반병동 간호사의 근무 환경, 역할갈등, 직무 배태성의 차이를 비교하기 위하여 independent t-test로 분석하였다.

- 간호 · 간병통합서비스 병동과 일반병동 간호사의 근무 환경, 역할갈등, 직무 배태성의 관계를 확인하기 위하여 Spearman 상관계수로 파악하였다.

\section{6. 윤리적 고려}

이 연구의 자료 수집을 위해 서울시 소재 $\mathrm{K}$ 병원의 생명
윤리위원회의 승인을 받은 후(승인번호: $\mathrm{KBSMC}$ ***********_****) 설문을 시행하였다. 연구자는 연구대상자에게 연 구의 개요, 목적과 절차 등을 설명 후 서면동의서를 받았 고, 응답내용은 연구 목적 외에 노출되지 않으며 비밀이 보장되는 것과 자발적으로 참여하며 원하지 않을 경우 언 제든지 철회할 수 있음을 명시하고 실시하였다. 설문지 배 포는 연구자가 해당 병동에 방문하여 배포하였으며 취합 된 설문지는 별도로 제공된 수거 봉투 함에 대상자가 자발 적으로 설문지를 제출하도록 하였고, 시간 손실에 대한 보 상으로 답례품을 배부하였다. 획득한 연구대상자의 성명, 주민등록번호 등 개인 식별정보는 수집하지 않았으며 귀 하의 신원을 파악할 수 있는 기록은 비밀로 보장되며 대 상자의 개인정보가 유출되지 않도록 얻어지는 개인정보 는 별도의 코딩화 된 데이터로 이용하였고, 관련문서는 잠 금 장치가 있는 보관 장에 보관하였으며, 이 연구에서 얻 게 되는 자료는 연구 종료 후 3 년까지 보관 후 즉시 폐기 할 예정이다.

\section{III. 연구결과}

\section{1. 일반적 특성 및 동질성 검정}

이 연구대상자의 일반적 특성 및 두 군의 동질성 검정에 대한 결과는 Table 1 과 같다. 평균 연령은 간호·간병통 합서비스 병동 $27.93 \pm 3.67$ 세, 일반병동 $28.67 \pm 4.95$ 세 이였고, 임상경력은 간호 · 간병통합서비스 병동 평균 $57.04 \pm 44.49$ 개월, 일반병동 평균 $67.97 \pm 60.74$ 개월 이었다. 최종 학력은 간호 · 간병통합서비스 병동 $88.6 \%$ (62명), 일반병동 $85.5 \%$ (59명)으로 학사졸업이 가장 많 았으며 직위는 간호. 간병통합서비스 병동 $95.7 \%$ (67 명), 일반병동 $87.0 \%$ (60명)으로 일반 간호사가 많았다. 동질성 검정 결과 두 집단의 차이는 없었으나 과거 다른 병동에서의 교차 근무 여부는 간호 - 간병통합서비스 병 동 $70.0 \%$ (49명), 일반병동 $11.6 \%$ (8명)으로 차이가 있 었다(p〈.001). 
Table 1. General characteristics of participants

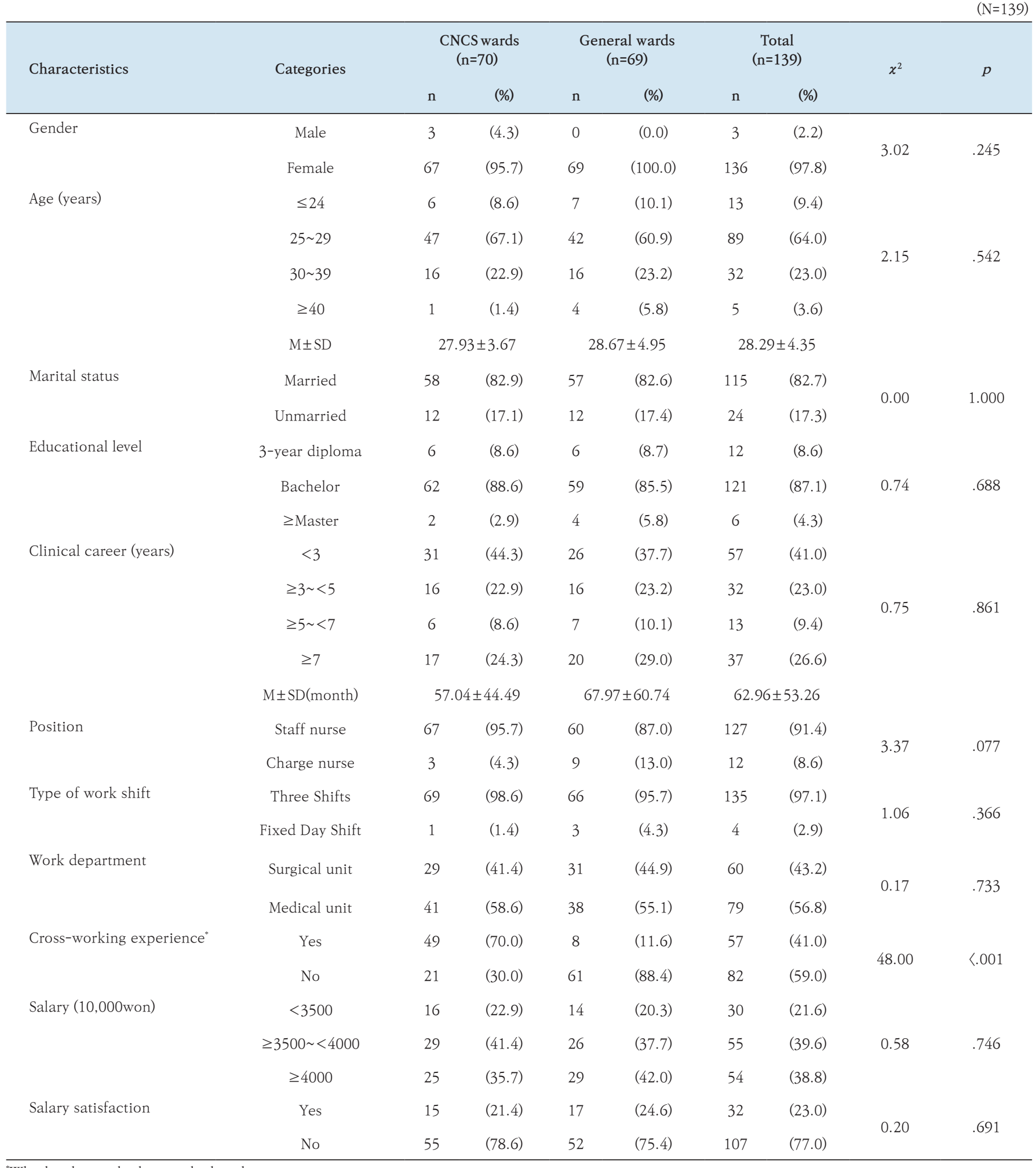

Whether he or she has worked in the past comparison group. 
2. 간호근무환경, 역할갈등, 직무 배태성의 차이

간호 - 간병통합서비스 병동과 일반병동 간호사의 근무 환경, 역할갈등, 직무 배태성을 비교한 결과는 Table 2 와 같다. 간호사가 인식하는 근무환경은 4점 만점 중 간호. 간병통합서비스 병동의 평균은 $2.92 \pm 0.48$ 점, 일반병동 의 평균은 $2.63 \pm 0.27$ 점으로 간호 - 간병통합서비스 병동 간호사가 일반병동 간호사보다 높게 나타났으며 통계적으 로 유의한 차이를 보였다( $\mathrm{t}=4.38, p<.001)$. 하위영역을 살 펴보면 '병원운영에 간호사의 참여' 간호 · 간병통합서비 스 병동 2.78점, 일반병동 2.57점( $(\mathrm{t}=2.72, p=.007)$, '양 질의 간호를 위한 기반' 간호 - 간병통합서비스 병동 3.05 점, 일반병동 2.83점 $(\mathrm{t}=3.47, p=.001)$, '간호 관리자의 능 력, 리더십, 간호사에 대한 지지 간호 - 간병통합서비스 병동 3.09점, 일반병동 2.86점 $(\mathrm{t}=2.92, p=.004)$, ‘충분한 인력과 물질적 지원' 간호 - 간병통합서비스 병동 2.85점, 일반병동 1.99점( $\mathrm{t}=8.96, p<.001)$, '간호사와 의사와의 협력관계' 간호 · 간병통합서비스 병동 2.78점, 일반병동 2.66점 $(\mathrm{t}=1.23, p=.218)$ 으로 나타나 '간호사와 의사와의 협력관계'영역을 제외한 근무환경의 하위영역에서 간호 . 간병통합서비스 병동이 일반병동 간호사보다 높게 나타났 으며 통계적으로도 유의한 차이를 보였다.

간호사가 인식하는 역할갈등은 5점 만점 중 간호 - 간병 통합서비스 병동의 평균은 $3.50 \pm 0.61$ 점, 일반병동의 평 균은 $3.70 \pm 0.55$ 점으로 간호 · 간병통합서비스 병동 간호 사가 일반병동 간호사보다 낮게 나타났으며 통계적으로 유의한 차이를 보였다(t=-2.09, $p=.038)$. 하위영역을 살 펴보면 '역할모호' 간호 · 간병통합서비스 병동 3.52점, 일 반병동 3.71점( $\mathrm{t}=-1.72, p=.087)$, '환경장애' 간호. 간 병통합서비스 병동 3.68점, 일반병동 4.15점 $(\mathrm{t}=-3.72, p$ 〈.001), '협조부족' 간호 - 간병통합서비스 병동 3.44점, 일반병동 3.70점 $(\mathrm{t}=-2.28, p=.024)$, '능력부족' 간호. 간병통합서비스 병동 3.38점, 일반병동 3.43점 $(\mathrm{t}=-0.43$, $p=.665)$ 으로 환경장애와 협조부족영역에서 간호 - 간병 통합서비스 병동이 일반병동 간호사보다 낮게 나타났으며 통계적으로도 유의한 차이를 보였다.
간호사가 인식하는 직무 배태성은 5점 만점 중 간호 - 간 병통합서비스 병동의 평균은 $3.35 \pm 0.56$ 점, 일반병동의 평균은 $3.33 \pm 0.48$ 점으로 간호 · 간병통합서비스 병동 간 호사가 일반병동 간호사보다 높게 나타났으나 통계적으로 유의한 차이는 보이지 않았다( $\mathrm{t}=0.22, p=.824)$. 하위영 역을 살펴보면 '적합성' 간호 · 간병통합서비스 병동 3.47 점, 일반병동 3.39점 $(\mathrm{t}=0.77, p=.442)$, '연계' 간호. 간 병통합서비스 병동 3.54점, 일반병동 3.61점 $(\mathrm{t}=-0.71$, $p=.447)$, ‘희생' 간호 · 간병통합서비스 병동 3.07점, 일 반병동 3.07점 $(\mathrm{t}=-0.03, p=.974)$ 으로 하위영역 모두 통 계적으로 유의한 차이는 없었다.

\section{3. 간호근무환경, 역할갈등, 직무 배태성 간의 관계}

간호 · 간병통합서비스 병동과 일반병동 간호사의 근무 환경, 역할갈등, 직무 배태성 간의 관계는 Table 3 과 같 다. 간호 - 간병통합서비스병동 간호사는 간호근무환경 과 역할갈등 사이에서 통계적으로 유의한 음의 상관관계 를 보이고 있고(r=-.36, $p=.002)$, 간호근무환경과 직무 배 태성 사이에는 통계적으로 유의한 양의 상관관계를 보이 며( $\mathrm{r}=.50, p=\langle .001)$, 역할갈등과 직무 배태성 사이에서 는 통계적으로 유의한 음의 상관관계를 보이고 있었다(r=.27, $p=.024)$. 일반병동 간호사는 간호근무환경과 역할갈 등 사이에서 통계적으로 유의한 음의 상관관계를 보이고 있고 $(\mathrm{r}=-.43, p=<.001)$, 간호근무환경과 직무 배태성 사 이에는 통계적으로 유의한 양의 상관관계를 보이며(r=.50, $p=\langle .001)$, 역할갈등과 직무 배태성 사이에서는 통계적으 로 유의하지 않았다( $\mathrm{r}=-.15, p=.215)$. 
Table 2. Differences in work environment, role conflict, and job embeddedness between CNCS ward nurses and general ward nurses

\begin{tabular}{|c|c|c|c|c|c|c|}
\hline \multirow{2}{*}{ Variables } & \multicolumn{2}{|c|}{$\begin{array}{l}\mathrm{CNCS}^{*} \text { wards } \\
\quad(\mathrm{n}=70)\end{array}$} & \multicolumn{2}{|c|}{$\begin{array}{c}\text { General wards } \\
\quad(n=69)\end{array}$} & \multirow{2}{*}{$\mathrm{t}$} & \multirow{2}{*}{$p$} \\
\hline & Mean & SD & Mean & SD & & \\
\hline Nursing workenvironment & 2.92 & 0.48 & 2.63 & 0.27 & 4.38 & $<.001$ \\
\hline Nurse participation in hospital affairs & 2.78 & 0.53 & 2.57 & 0.36 & 2.72 & .007 \\
\hline Nursing foundations for quality of care & 3.05 & 0.42 & 2.83 & 0.31 & 3.47 & $\langle .001$ \\
\hline Nurse manager ability, leadership, and support of nurses & 3.09 & 0.54 & 2.86 & 0.34 & 2.92 & .004 \\
\hline Staffing and resource adequacy & 2.85 & 0.64 & 1.99 & 0.46 & 8.96 & $\langle .001$ \\
\hline Collegial nurse-physician relations & 2.78 & 0.65 & 2.66 & 0.51 & 1.23 & .218 \\
\hline Role conflict & 3.50 & 0.61 & 3.70 & 0.55 & -2.09 & .038 \\
\hline Role ambiguous & 3.52 & 0.68 & 3.71 & 0.62 & -1.72 & .087 \\
\hline Environmental obstacle & 3.68 & 0.77 & 4.15 & 0.69 & -3.72 & $<.001$ \\
\hline Lack cooperation & 3.44 & 0.64 & 3.70 & 0.70 & -2.28 & .024 \\
\hline Lack ability & 3.38 & 0.65 & 3.43 & 0.67 & -0.43 & .665 \\
\hline Job embeddedness & 3.35 & 0.56 & 3.33 & 0.48 & 0.22 & .824 \\
\hline Links & 3.47 & 0.63 & 3.39 & 0.62 & 0.77 & .442 \\
\hline Fit & 3.54 & 0.59 & 3.61 & 0.54 & -0.71 & .477 \\
\hline Sacrifice & 3.07 & 0.67 & 3.07 & 0.53 & -0.03 & .974 \\
\hline
\end{tabular}

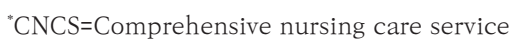

Table 3. The relationship between work environment, role conflict, and Job embededness between CNCS ward nurses and general ward nurses

\begin{tabular}{|c|c|c|c|c|c|c|c|c|c|}
\hline \multirow{3}{*}{ Variables } & \multicolumn{3}{|c|}{ Total $(n=139)$} & \multicolumn{3}{|c|}{$\mathrm{CNCS}^{*}$ wards $(\mathrm{n}=70)$} & \multicolumn{3}{|c|}{ General wards $(n=69)$} \\
\hline & $\begin{array}{l}\text { Nursing work } \\
\text { environment }\end{array}$ & $\begin{array}{l}\text { Role } \\
\text { conflict }\end{array}$ & $\begin{array}{c}\text { Job } \\
\text { embeddedness }\end{array}$ & $\begin{array}{l}\text { Nursing work } \\
\text { environment }\end{array}$ & $\begin{array}{c}\text { Role } \\
\text { conflict }\end{array}$ & $\begin{array}{c}\text { Job } \\
\text { embeddedness }\end{array}$ & $\begin{array}{l}\text { Nursing work } \\
\text { environment }\end{array}$ & $\begin{array}{c}\text { Role } \\
\text { conflict }\end{array}$ & $\begin{array}{c}\text { Job } \\
\text { embeddedness }\end{array}$ \\
\hline & $\mathrm{r}(p)$ & $r(p)$ & $\mathrm{r}(p)$ & $\mathrm{r}(p)$ & $\mathrm{r}(p)$ & $\mathrm{r}(p)$ & $\mathrm{r}(p)$ & $\mathrm{r}(p)$ & $\mathrm{r}(p)$ \\
\hline $\begin{array}{l}\text { Nursing work } \\
\text { environment }\end{array}$ & 1.000 & & & 1.000 & & & 1.000 & & \\
\hline Role conflict & $-.40(.001)$ & 1.000 & & $-.36(.002)$ & 1.000 & & $-.43(<.001)$ & 1.000 & \\
\hline Job embeddedness & $.44(<.001)$ & $-.200(.018)$ & 1.000 & $.50(<.001)$ & $-.27(.024)$ & 1.000 & $.50(<.001)$ & $-.15(.215)$ & 1.000 \\
\hline
\end{tabular}

${ }^{*} \mathrm{CNCS}=$ Comprehensive nursing care service 


\section{IV. 고찰}

이 연구는 간호 - 간병통합서비스 병동 간호사와 일반병 동 간호사의 근무환경, 역할갈등, 직무 배태성의 차이를 확 인하고, 근무환경, 역할갈등, 직무 배태성 간의 관계를 파 악함으로써, 간호 - 간병통합서비스 병동 도입에 따른 간호 의 질적 향상을 위한 기초자료를 제공하기 위해 시도되었 으며 연구결과를 중심으로 논의하면 다음과 같다.

간호 · 간병통합서비스 병동과 일반병동 간호사의 근무 환경에 대해 살펴보면 4점 만점 중 간호 - 간병통합서비스 병동의 평균은 2.92점, 일반병동의 평균은 2.63점으로 간 호 · 간병통합서비스 병동 간호사가 일반

병동 간호사보다 높게 나타났으며 통계적으로도 유의한 차이를 보였다. Lake [12]가 개발한 PES-NWI의 점수 산정 방법은 전체항목의 평균값을 이용하는데, 2.5 점을 기준으 로 그 이상인 경우 간호사가 자신의 근무환경이 좋다는 것 에 동의하는 것으로 보았고, 2.5 점 미만인 경우 그렇지 않 은 것으로 판정하였다. 연구에서 사용된 한국어판 간호업무 환경 측정도구 $\mathrm{K}-\mathrm{PES}-\mathrm{NWI}$ 의 전체평균은 2.58점이었고 [24], 이 연구에서도 두 군 모두 자신의 근무환경이 좋다고 동의하였으나 간호 - 간병통합서비스 병동의 간호사가 일반 병동 간호사보다 평균점수가 높게 나타나 자신의 근무환경 에 대해 더 긍정적으로 인식하고 있는 것으로 나타났다. 근 무환경의 하위영역을 보면 '간호 관리자의 능력, 리더십, 간 호사에 대한 지지' 영역이 간호 - 간병통합서비스 병동 3.09 점, 일반병동 2.86점으로 두 군 모두 가장 높게 나타났는 데, 이는 K-PES-NWI [24]도구의 문항을 바탕으로 해석하 면 간호 업무수행과 문제해결에 있어서 간호 관리자의 지지 적인 태도와 지원을 받는 것을 중요시 생각하고 있다는 것 으로 이해할 수 있다. '간호사와 의사와의 협력 관계' 영역 에서는 간호 · 간병통합서비스 병동 2.78점, 일반병동 2.66 점으로 두 군간의 통계적으로 유의한 차이는 없었는데, 이 는 간호 - 간병통합서비스 병동에서의 의사 인력배치와 업 무방법 등의 큰 차이가 없는 것이 요인으로 Park 등[2]의 연 구결과와 동일 하였다. 근무환경의 하위영역 중 '충분한 인 력과 물질적 지원' 영역에서 일반병동 1.99 점으로 가장 낮
은 점수를 나타냈다. 이는 간호 - 간병통합서비스 병동에 간 호인력 및 보조인력의 배치가 상대적으로 많아 두 병동 간 의 인력과 물질적 지원의 큰 차이가 있고[6], 간호 인력수가 더 많은 근무환경이 간호업무성과에 긍정적인 영향을 주어 [26] 간호 - 간병통합서비스 병동에 근무하는 간호사의 근 무환경에 대한 만족도가 높게 나타난 것으로 이해할 수 있 다. 또한 보조인력 및 충분한 물질의 지원으로 환자 들과의 직접간호시간이 더 많이 주어짐으로써[11], 양질의 간호를 제공할 수 있는 기회가 증가되어 본인의 근무환경에 긍정적 으로 인식하고 있음으로 파악된다. 따라서 간호 · 간병통합 서비스 병동과 일반병동 간의 다른 근무환경 차이에서 느낄 수 있는 상대적인 이질감을 줄이며 두 병동 간에 특성에 맞 는 효율적인 인력관리 및 시스템적 지원을 통한 근무환경개 선의 방안 모색이 요구된다.

간호 · 간병통합서비스 병동과 일반병동 간호사의 역할 갈등에 대해 살펴보면 5점 만점 중 간호·간병통합서비스 병동의 평균은 3.50점, 일반병동의 평균은 3.70점으로 간 호 - 간병통합서비스 병동 간호사가 일반병동 간호사보다 낮게 나타났으며 통계적으로 유의한 차이를 보였다. 역할 갈등의 하위영역을 살펴보면 간호 · 간병통합서비스 병동 과 일병병동 간호사 모두 환경장애 요인이 가장 높았으며 간호 · 간병통합서비스 병동 3.68점, 일반병동 4.15점으 로 환경부분에서 일반병동 간호사의 역할갈등 정도가 높고 통계적으로 유의한 차이를 보였다. 병원간호사들의 역할 갈등의 심각성을 다룬 연구[15]에서 간호업무에 비해 간호 인력이 부족할 때, 정해진 시간 내에 해야 할 일이 너무 많 을 때, 역할갈등을 가장 심각하게 경험하고 있었는데 앞서 다루었던 근무환경과도 밀접하게 연관됨을 알 수 있다. 그 외 역할갈등의 하부요인 결과로 두 군 모두 역할모호, 협조 부족, 능력부족 순으로 나타났으며, 간호 · 간병통합서비스 병동보다 일반병동 간호사의 역할갈등 정도는 두 군 모두 높게 나타났으나 역할 모호 문항과 능력부족 문항은 통계 적으로 유의하지 않았다. 간호 - 간병통합서비스 병동 간호 사보다 일반병동의 간호사들이 환경장애로 인한 역할갈등 을 더 많이 경험하고 있는 것으로 나타났는데, 환경장애 요 인의 문항을 보면 '내가 맡은 일은 처리하는데 필요한 일손 
과 기구가 부족할 때', ‘충분한 인원과 시설 또는 기구가 확 보되지 못한 상황에서 간호업무를 수행해야 할 때', '간호 수행 시 필요한 행정 및 시설의 지원을 받지 못했을 때'등 으로 구성되어 있다. 이를 해석하면 업무에 있어서 간호사 의 능력이나, 업무수행에 필요한 전문지식과 기술부족으로 느끼는 갈등보다 인원과 시설이 확보되지 못한 상황에서 의 간호업무수행이 역할갈등에 있어서 큰 부분으로 작용함 으로 역할갈등을 경험하는 이유 중의 하나로 판단된다. 하 지만 이를 일반화하는 데는 제한이 있고, 또한 간호 - 간병 통합서비스 병동과 일반병동의 역할 특성에 맞는 세분화된 역할갈등 측정도구가 없어 도구개발이 필요하며 반복적인 연구를 통한 결과 확인이 필요하다.

간호 · 간병통합서비스 병동과 일반병동 간호사의 직무 배태성을 살펴보면 5점 만점 중 간호 - 간병통합서비스 병 동의 평균은 3.35 점, 일반병동의 평균은 3.33점으로 간 호 - 간병통합서비스 병동 간호사가 일반병동 간호사보다 높게 나타났으나 통계적으로 유의한 차이는 보이지 않았 다. 하위영역을 살펴보면 연계영역이 간호 · 간병통합서비 스 병동의 평균은 3.54점, 일반병동의 평균은 3.61점으 로 두 군 모두 점수가 가장 높았고, 그 다음은 적합성 영역 이 간호 - 간병통합서비스 병동 평균은 3.47점, 일반병동 3.39점으로 높았으며, 희생영역이 간호 · 간병통합서비스 병동의 평균은 3.07점, 일반병동의 평균은 3.07점으로 두 군 모두 점수가 가장 낮았다. 이는 간호 업무 형태가 교대 근무로 인한 연속성 있는 근무형태로 동료들과 지속적으로 상호 작용하며[27], 간호의 업무 특성상 여러 부서와 여러 직종들 과도 관계 형성이 되어있어[15] 연결 정도가 높은 요인으로 파악되고 또한 희생영역의 점수가 낮은 것은 간 호사는 전문직으로 비교적 재취업의 기회가 많고, 여러 분 야로의 전향이 가능하여[22] 조직을 떠남으로써 잃게 되는 물리적, 심리적 손해의 정도가 낮기 때문으로 파악된다.

간호근무환경, 역할갈등, 직무 배태성 간의 관계에서 간 호 - 간병통합서비스 병동에서의 간호근무환경과 역할갈등 사이에는 음의 상관관계, 간호근무환경과 직무 배태성 사 이에는 양의 상관관계, 역할갈등과 직무 배태성 사이에는 음의 상관관계를 보이고 있었고 모두 통계적으로 유의하였
다. 일반병동에서는 간호근무환경과 역할갈등 사이에는 통 계적으로 유의한 음의 상관관계, 간호근무환경과 직무 배 태성 사이에는 통계적으로 유의한 양의 상관관계를 보였지 만, 역할갈등과 직무 배태성 간의 상관관계는 존재하지 않 았다. 이처럼 간호근무환경에 만족할수록 직무 배태성에 긍정적으로 작용하고 있어, 간호인력 배치 및 물질적 지원 과 같은 근무환경개선 도모는 간호의 질 향상에 기여할 것 으로 사료된다.

이 연구의 대상자는 서울 소재의 일개 상급종합병원의 간 호사를 대상으로 임의 표출하였으므로 연구 결과를 일반 화하여 확대 해석하는 것은 제한이 있다. 하지만 간호 - 간 병통합서비스 병동이 확대 운영되고 있는 시점에서 간호 . 간병통합서비스 병동과 일반병동 간의 근무환경, 역할갈 등, 직무 배태성을 비교, 분석하고 관계를 파악함으로써 간 호·간병통합서비스 병동 도입에 따른 병동 운영 개선 및 간호의 질적 향상을 위한 기초자료를 제공한 연구로 의의 가 있다.

\section{V. 결론}

이 연구는 간호 · 간병통합서비스 병동 간호사와 일반병 동 간호사의 근무환경, 역할갈등, 직무 배태성을 비교, 분 석하고 근무환경, 역할갈등, 직무 배태성 간의 관계 확인을 위해 수행되었다. 이상의 연구결과를 종합해 볼 때 간호. 간병통합서비스 병동 간호사가 일반병동 간호사보다 자신 의 근무환경에 대해 더 긍정적으로 인식하며 만족하고 있 었고 역할갈등 정도는 낮았으나 직무 배태성에는 차이를 보이지 않았다. 또한 본인의 근무 환경에 만족할 수록 직 무 배태성이 높아 짐을 확인할 수 있었다. 이 연구 결과 간 호 · 간병통합서비스 병동의 도입은 간호사들의 직무 배태 성을 유지하면서, 보다 나은 근무환경 개선과 팀내 역할 정 립 강화로 나타났다. 이러한 결과는 간호인력 배치, 물질적 지원과 같은 근무환경개선을 구현하는 것이 간호의 질 향 상에 기여함을 보여주며, 간호 - 간병통합서비스 병동의 도 입을 확대할 필요가 있음을 보여준다. 이 연구의 결과를 토 대로 다음과 같은 후속 연구를 제언한다. 
이 연구는 서울시 소재의 일개 상급종합병원에 근무하는 간호 - 간병통합서비스 병동과 일반병동에 근무하는 간호 사만을 대상으로 하였으므로 연구결과의 일반화를 위해 향 후 다양한 지역 및 다양한 의료기관 종별로 연구 대상자를 확대한 반복 연구를 제언한다.

간호 - 간병통합서비스 병동과 일반병동 간의 다른 근무 환경 차이에서 느낄 수 있는 간호사들의 상대적인 이질감 을 줄이기 위해 두 병동 간의 특성에 맞는 간호표준수립 및 근무환경개선 방안과 정책 개발을 제언한다.

\section{VI. 참고문헌}

1. Hwang NM. Policy directions for the assurance of quality nursing and care Services. Labor Review. 2006;18:71-6.

2. Park IS, Kim JH, Hong HJ, Kim HS, Han IS, Lee SY. Comparing satisfaction and importance of nursing care nursing work environment, nurse's intention to work between comprehensive nursing care unit and general nursing care unit. Journal of Korean Clinical Nursing Research. 2018;24(1):34-43.

3. Korean Nursing Association. Development of standard curriculum and guidelines for carers. Seoul, Korea: Ministry of Health and Welfare; 2007.

4. Lee YM, Lee HH, Jung JH, Yang JK, Lee JE, Kim SK. A study about compassion fatigue, compassion satisfaction and burnout in comprehensive nursing care and general ward nurses. Journal of Korean Clinical Nursing Research. 2018;24(2):188-96.

5. National Health Insurance Service. Comprehensive nursing care service's standard operating manual. [Internet]. Seoul, Korea: National Health Insurance Service; 2017 [cited 2019 Apr 12]. Available from: http://www.nhis.or.kr/bbs7/boards/B0040/24586.

6. National Health Insurance Service. Guide comprehensive nursing care service. [Internet]. Seoul, Ko- rea: National Health Insurance Service; 2017 [cited 2019 Apr 12]. Available from: https://www.nhis. or.kr/bbs7/boards/B0040/28196.

7. National Health Insurance Service. press release [Internet]. Seoul, Korea: National Health Insurance Service; 2018 [cited 2019 Apr 12]. Available from: http://www.nhis.or.kr/bbs7/boards/B0039/28141.

8. Jung YA, Sung KM. A comparison of patients' nursing service satisfaction, hospital commitment and revisit intention between general care unit and comprehensive nursing care unit. Journal of Korean Academy of Nursing Administration. 2018;24(1):30-9.

9. Kim JH, Kim SJ, Park ET, Jeong SY, Lee EH. Policy issues and new direction for comprehensive nursing service in the national health insurance. Journal of Korean Academy of Nursing Administration. 2017;23(3):312-22.

10. Park JH, Lee MH. Effects of nursing and care=giving integrated service on nursing work performance, nurses' job satisfaction and patient safety. Journal of Korean Academic Society of Home Health Care Nursing. 2017;24(1):14-22.

11. Park KO, Yu M, Kim JK. Experience of nurses participating in comprehensive nursing care. Journal of Korean Academy of Nursing Administration. 2017;23(1): 76-89.

12. Lake ET. Development of the practice environment scale of the nursing work index. Research in Nursing \& Health. 2002;25(3):176-88.

13. Ahn SH, Jung SH, You JH, Lee MA. Nursing tasks and practice environment for nursing work perceived by nurses working on comprehensive wards versus general wards. Journal of Korean Academy of Nursing Administration. 2018;24(1):10-20.

14. Kim MS, Park SY. Development of a role conflict scale for clinical nurses. Journal of Korean Acade- 
my of Nursing. 1995;25(4):741-50.

15. Lee EH, Cho KS, Son HM, Yi YJ, Yoo CS. Frequency and severity of the nurses' role conflict in the hospital nurses. Journal of Korean Clinical Nursing Research. 2013;19(1):81-95.

16. Kim TJ, You JO. Comparative study of clinical nurses' role conflict, emotional labor and nursing performance between comprehensive nursing care service wards and general wards. Journal of Muscle and Joint Health. 2018;25(1):12-20.

17. Kang KN. Factors influencing turnover intention of nurses in small-medium sized hospitals. Journal of Korean Academy of Nursing Administration. 2012;18(2):155-65.

18. Mitchell TR, Holtom BC, Lee TW, Sablynski CJ, Erez M. Why people stay: using job embeddedness to predict voluntary turnover. Academy of Management Journal. 2001;44(6):1102-21.

19. Kang KH, Chae YR, Park SY. Job embeddedness of korean clinical nurses: A literature review. Korean Journal of Occupational Health Nursing. 2018;27(3):139-51.

20. Kang KH, Lim YJ. Influence of professionalism, role conflict and work environment in clinical nurses with expanded role on job enbeddedness. Journal of Korean Academy of Nursing Administration. 2016;22(5):424-36.

21. Kim EH, Lee EJ, Choi HJ. Mediation effect of organizational citizenship behavior between Job embeddedness and turnover intention in Hospital Nurses. Journal of Korean Academy of Nursing Administration. 2012;18(4):394-401.

22. Kim EH, Lee EJ. Mediation and moderation effects of job embeddedness between nursing performance and turnover intention of nurses. Journal of the Korea Academia-Industrial Cooperation Society.
2014;15(8):5042-52.

23. Kang IS, KIM YH. Factors Influencing turnover intention of nurses participating in integrated nursing care service. Journal of the Korean Data Analysis Society. 2018;20(2):1063-75.

24. Cho EH, Choi MN, Kim EY, Yoo IY, Lee NJ. Construct validity and reliability of the korean version of the practice environment scale of nursing work index for korean nurses. Journal of Korean Academy of Nursing. 2011;41(3):325-32.

25. House RJ, Schuler RS, Levanoni E. Role conflict and ambiguity scales: reality or artifacts? Journal of Applied Psychology. 1983;68(2):334-7.

26. Lee KA, Lee SH. A comparative study on the operation status of comprehensive nursing care ward. Journal of Muscle and Joint Health. 2018;25(3):196204.

27. Kim JK, Kim MJ, Kim SY, Yu M, Lee KA. Effects of general hospital nurses' work environment on job embeddedness and burnout. Journal of Korean Academy of Nursing Administration. 2014;20(1):69-81.

28. Kang HC, Yeon KP, Han ST. A review on the use of effect size in nursing research. Journal of Korean Academy of Nursing Administration. 2015;45(5):641-9. 